\title{
Big Data-Enabled Solutions Framework to Overcoming the Barriers to Circular Economy Initiatives in Healthcare Sector
}

\author{
Yiğit Kazançoğlu ${ }^{1}{ }^{\oplus}$, Muhittin Sağnak ${ }^{2} \mathbb{D}$, Çisem Lafcı ${ }^{1}$, Sunil Luthra ${ }^{3}$, Anil Kumar ${ }^{4}$ and Caner Taçoğlu ${ }^{5, *}$ \\ 1 Department of International Logistics Management, Faculty of Business, Yaşar University, \\ İzmir 35100, Turkey; yigit.kazancoglu@yasar.edu.tr (Y.K.); cisem.lafci@gmail.com (Ç.L.) \\ 2 Department of Information Management, İzmir Katip Celebi University, İzmir 35620, Turkey; \\ muhittin.sagnak@ikcu.edu.tr \\ 3 Department of Mechanical Engineering, Ch. Ranbir Singh State Institute of Engineering and Technology, \\ Jhajjar-124103, India; sunilluthra1977@gmail.com \\ 4 Guildhall School of Business and Law, London Metropolitan University, London N7 8DB, UK; \\ a.kumar@londonmet.ac.uk \\ 5 Department of Industrial Engineering, Faculty of Engineering, İzmir University of Economics, \\ İzmir 35330, Turkey \\ * Correspondence: caner.tacoglu@ieu.edu.tr
}

check for

updates

Citation: Kazançoğlu, Y.; Sağnak, M.; Lafcı, Ç.; Luthra, S.; Kumar, A.; Taçoğlu, C. Big Data-Enabled Solutions Framework to Overcoming the Barriers to Circular Economy Initiatives in Healthcare Sector. Int. J. Environ. Res. Public Health 2021, 18, 7513. https://doi.org/10.3390/ ijerph18147513

Academic Editor: Paul B. Tchounwou

Received: 13 May 2021

Accepted: 9 July 2021

Published: 14 July 2021

Publisher's Note: MDPI stays neutral with regard to jurisdictional claims in published maps and institutional affiliations.

Copyright: (c) 2021 by the authors. Licensee MDPI, Basel, Switzerland. This article is an open access article distributed under the terms and conditions of the Creative Commons Attribution (CC BY) license (https:/ / creativecommons.org/licenses/by/ $4.0 /)$.
Abstract: Ever-changing conditions and emerging new challenges affect the ability of the healthcare sector to survive with the current system, and to maintain its processes effectively. In the healthcare sector, the conservation of the natural resources is being obstructed by insufficient infrastructure for managing residual waste resulting from single-use medical materials, increased energy use, and its environmental burden. In this context, circularity and sustainability concepts have become essential in healthcare to meliorate the sector's negative impacts on the environment. The main aim of this study is to identify the barriers related to circular economy (CE) in the healthcare sector, apply big data analytics in healthcare, and provide solutions to these barriers. The contribution of this research is the detailed examination of the current healthcare literature about $\mathrm{CE}$ adaptation, and a proposal for a big data-enabled solutions framework to barriers to circularity, using fuzzy best-worst Method (BWM) and fuzzy VIKOR. Based on the findings, managerial, policy, and theoretical implementations are recommended to support sustainable development initiatives in the healthcare sector.

Keywords: circular economy; sustainable development; healthcare sector; big data tools; barriers; fuzzy best-worst; fuzzy VIKOR; waste issues

\section{Introduction}

The healthcare sector is undergoing significant changes that constantly create new challenges, hindering the implementation of the current model, and negatively affecting it on various levels, especially in developing countries [1]. The usage of resources, materials, and energy has been increased dramatically in the healthcare sector over the years [2]. This increasing resource need and demand in the health sector has led to an increase in the usage of disposable medical equipment, and single-use medical supplies. A large number of these healthcare supplies are used once and then discarded [3], which causes huge disruptions and burdens from the environmental perspective. Most of these disposable medical types of equipment are plastic products that are frequently used for various medical applications. The non-biodegradable nature of these has a harmful effect on the environment [4]. As a result of these emerging trends, the healthcare sector itself has been affected, and seeks sustainable solutions.

Additionally, the effect of the COVID-19 pandemic has placed tremendous strains on medical equipment movements resulting from supply chain disruptions, on aspects such as the reverse action of disposal and recycling practices to eliminate infectious medical wastes $[5,6]$. The growing amount of hazardous and contagious healthcare waste created as 
a result of advances in patient treatment has posed a significant threat to the entire planet [5]. The healthcare sector accounts for approximately 4.6 percent of global greenhouse-gas emissions [7]. From the viewpoint of healthcare, the volume of waste generated during these periods of outbreak crisis has provided various opportunities for the implementation of principles driven by the Circular Economy (CE), invovlving treatment of medical waste and the local procurement/recovery of essential raw materials $[8,9]$.

The circular economy can be described as a restorative and regenerative approach that contrasts with a linear economy, which regards resources and energy as purely disposable [7]. One of the main principles of $\mathrm{CE}$ is to protect the value and quality of products and materials, and maintain their value in the economic system by extending the end-of-life cycle of the product $[10,11]$. As a result, while CE can help address shortages on the input side of the healthcare industry during the COVID-19 outbreak, the generation of hazardous waste inhibits CE adoption on the output side [9]. The reason for this was supply problems during the pandemic, such as lack of raw materials in the face-to-face transaction structure, and incompatibility between needs and available products, including sizes and quantities $[8,12]$.

Similar to CE, monitoring generated waste requires the use of several networks of smart technology such as artificial intelligence (AI), big data, and the Internet of Things (IoT) $[5,13]$. Therefore, Industry 4.0 provides tremendous opportunities for $\mathrm{CE}$, in which products are being remanufactured, reused, and recycled at end-of-life cycles [13]. Especially, ongoing advancements in the healthcare field, coupled with the rise of big data, have culminated in a rapid and vast expansion of medical data [14]. Big data analytics (BDA) can create evidence for better care delivery by allowing the extraction of valuable information from collected data patterns in research, clinical care environments, and operational settings. In this context, industrial and academic experts are becoming progressively more interested in the potential benefits of big data technology in healthcare [15].

The absence of suitable infrastructure, and the existence of barriers to achieve an efficient healthcare waste management system, particularly in emerging economies, have been cited as a significant challenge in addressing waste [5,16-18]. Additionally, the current literature on the healthcare sector shows a gap in terms of the connection between $\mathrm{CE}$ and I4.0 technologies, particularly big data analytics. Thus, big data analytics can be a promoter force in the overcoming of healthcare barriers due to the requirement for more expanded applications of I4.0 technologies. In this context, the following research questions (RQs) addressing the research gap are proposed:

RQ1: What are the barriers to CE and these indicators' significance in the healthcare sector?

RQ2: Can big data analytics and its tools be applied to the healthcare sector to propose solutions in terms of circularity practices?

In order to address the aforementioned RQs, the current literature on the healthcare sector was scrutinized, and CE perspectives were adopted to manage sustainability-related barriers Next, big data analytics and its tools were used for proposing solutions for each barrier to be overcome. For this purpose, this study initially points out the barriers related to $\mathrm{CE}$ in the healthcare sector. Following this, big data analytics was adapted to the healthcare sector to provide solutions. In this context, the main contribution of this study is the detailed examination of the current healthcare literature about $\mathrm{CE}$ adaptation, and the proposal for big data-enabled framework that matches and ranks the solutions to circularity-oriented barriers using fuzzy best-worst method (BWM) and fuzzy VIKOR methods.

The paper is structured as follows. In Section 2, theoretical background about barriers to $\mathrm{CE}$ in healthcare sector and big data tools are presented and explained in detail. In Section 3, the methodology is presented. In Section 4, the case study is discussed. In Section 5, discussions, and managerial, policy, and theoretical implications emerging from the findings are presented. Finally, in Section 6, the concluding remarks are presented. 


\section{Theoretical Background}

\subsection{Samples Preparation}

The below-mentioned barriers to $\mathrm{CE}$ adoption in the healthcare sector, derived from the relevant literature, were scrutinized. These barriers to $C E$, drawn from the literature, were grouped under various dimensions. These determined barriers were classified under eight sub-dimensions as economic and financial, policy, organizational, environmental, social, human resources, managerial, and operational and technology. Table 1 presents the barriers to circularity for healthcare sector.

Table 1. Barriers to CE in Healthcare Sector.

\begin{tabular}{|c|c|c|c|}
\hline Main Dimensions & Code & Barriers & References \\
\hline \multirow{4}{*}{ Economic and Financial Barriers } & B1 & High cost requirement for circular technologies and implementations & {$[2,13,19-23]$} \\
\hline & B2 & $\begin{array}{l}\text { Lack of financial capabilities and resources on } \\
\text { environmental investments }\end{array}$ & {$[19,23-26]$} \\
\hline & B3 & $\begin{array}{l}\text { Challenges in identifying the economic benefits of } \\
\text { environmental investments }\end{array}$ & [23] \\
\hline & B4 & Lack of demand for eco-friendly medical supplies & {$[20,21]$} \\
\hline \multirow{3}{*}{ Policy Barriers } & B5 & Lack of circular policies, incentives, and regulations in healthcare & {$[7,13,19-22,25-28]$} \\
\hline & B6 & Lack of favorable policies for using technology & [25] \\
\hline & B7 & $\begin{array}{l}\text { Unfavorable government legislation and execution on } \\
\text { circular healthcare }\end{array}$ & {$[4,19,25]$} \\
\hline \multirow{5}{*}{ Organizational Barriers } & B8 & Poor organizational design for CE principles & {$[20,21]$} \\
\hline & B9 & Current institutional misconceptions about sustainability & {$[20,22]$} \\
\hline & B10 & Inconsistency of healthcare cultures and values with CE principles & {$[24,29-34]$} \\
\hline & B11 & Lack of established standards for $\mathrm{CE}$ activities in healthcare & {$[20,21]$} \\
\hline & B12 & Lack of organizational readiness for CE activities & {$[24,31,33,35-38]$} \\
\hline \multirow{3}{*}{$\begin{array}{l}\text { Environmental } \\
\text { Barriers }\end{array}$} & B13 & Lack of safe management of medical waste in healthcare & {$[13,39]$} \\
\hline & B14 & Lack of environmental management & {$[7,27,40,41]$} \\
\hline & B15 & Single-use medical devices and supplies & {$[2,7,42]$} \\
\hline \multirow{3}{*}{ Social Barriers } & B16 & Lack of public perception and commitment to environmental issues & {$[4,20,21,23]$} \\
\hline & B17 & Lack of awareness about circularity & {$[19,24,36,43-46]$} \\
\hline & B18 & Lack of public interest and reaction & [21] \\
\hline \multirow{4}{*}{ Human Resources Barriers } & B19 & Resistance to change & {$[20,25,47,48]$} \\
\hline & B20 & $\begin{array}{l}\text { Limited knowledge-base on environmental problems among } \\
\text { employees for CE activities }\end{array}$ & {$[23,24,31,35,36,49,50]$} \\
\hline & B21 & Lack of know-how, training, and expertise training for $\mathrm{CE}$ activities & {$[19-21,25,26]$} \\
\hline & B22 & Limited HR capacity for CE activities & {$[24,31,33,35-38]$} \\
\hline \multirow{3}{*}{ Managerial Barriers } & B23 & Lack of top management support and commitment about circularity & $\begin{array}{l}{[19-21,23,25,26,30,31,34-} \\
\quad 36,45,48,49,51,52]\end{array}$ \\
\hline & B24 & Proactive strategies for environmental burden & {$[23,27]$} \\
\hline & B25 & Conflict of interest among stakeholders & {$[20,48]$} \\
\hline \multirow{6}{*}{$\begin{array}{l}\text { Operational and Technology } \\
\text { Barriers }\end{array}$} & B26 & $\begin{array}{l}\text { Challenges in identifying the impacts of environmental practices to } \\
\text { clinical processes }\end{array}$ & [23] \\
\hline & B27 & Capacity building & {$[24,29-31,44,46,49,52-55]$} \\
\hline & B28 & Complexity of circularity in healthcare systems & {$[22,47]$} \\
\hline & B29 & Poor infrastructure & {$[5,13,24,46,49,51,53,54,56,57]$} \\
\hline & B30 & Lack of recycling options in medical supplies & [4] \\
\hline & B31 & Limited IT infrastructure and technologies in medical informatics & {$[25,26,58]$} \\
\hline
\end{tabular}

Technologies required for CE principle implementations in healthcare can have beneficial effects on the environment, including maximizing efficiency in usage of energy, 
providing cost-efficient solutions, and the elimination of the natural resource waste. However, the adoption of these technologies, equipment, and solutions requires high-cost investments. Especially, with the impacts of the COVID-19, the healthcare sector has experienced a rising shortage of medical supplies, thus, the pandemic created a devastating financial burden. In addition to the pandemic, the healthcare sector faces challenges arising from a lack of financial resources and capabilities, hindering investment in green technology and solutions and for environmentally circular applications [23,59]. The reason underlying individual hospitals and health systems' failure to give the required attention to these eco-friendly medical supplies is due to the challenges in identifying the economic benefits of environmental investments in the sector. One of the reasons for the lack of attention to these environmental investments is associated with healthcare's miscellaneous portfolio, which includes products of both low and high economic value [3,10]; thus, financial gains of these investments are difficult to determine.

Governments may have some shortcomings in CE-oriented policy-making, regulation, implementation, and incentives for the healthcare sector on waste generation, and policies for the management and improvement of this waste. As a result of the constraints caused by the lack of government laws and policies, waste produced within the healthcare system endangers the environment and human health in many ways, as they are not inspected and recycled. In this context, a key barrier to the health sector's transition to CE, a more sustainable option, is the lack of policies that enable health systems to adopt green-focused solutions and encourage this transition. To strengthen and accelerate the transition into a more circular and sustainable system for the healthcare sector, an important role will be played by emerging technologies. However, some views in the current literature suggest government policies, business models, and management decisions have the power not only to accelerate the implementation of suitable technologies, but also hinder it [16]. In this context, the lack of favorable policies for using technology and unfavorable government legislation is a key barrier to this transition in the health sector and requires immediate action.

Supply chain practices in a healthcare environment are deeply connected to organizational conditions, such as establishing partnerships, allocating responsibilities and authority, and coordinating and organizing interface processes $[20,60]$. Therefore, organizational barriers play a key role in establishing the organizational design, culture, value, and standards necessary for the adaptation of CE in the healthcare sector. Barriers towards CE are especially caused by deficiencies in healthcare systems' organizational culture, such as poor organizational design, misconceptions about sustainability issues, inconsistent healthcare culture and values, and lack of established standards for CE activities.

The current healthcare system jeopardizes natural resources, causing irrevocable damages to the environment. Therefore, safe management and treatment of resultant medical waste and disposals is essential for eliminating contagion and meliorating the standards for public health. Although safe management of medical waste and disposal is a requirement for the prevention and control of health-related infections, necessary to strengthen trust in services, and reduce the cost of service provision [61], this issue continues to impede the transition to CE. Additionally, the lack of environmental management contributes to the generation of hazardous chemical and substances, such as carbon/greenhouse emission, one of the most widely studied barrier in the literature for emerging countries [62-66]. The healthcare supply chain accounts for the vast majority of the sector's global greenhouse gas emissions. Moreover, the idea that single-use (disposable) medical devices and supplies are safer than reusable ones is one of the greatest drivers of the dominance of single-use devices in the healthcare supply chain [7].

Social barriers are also key challenges against CE implementation in the healthcare sector. For instance, lack of awareness regarding the concepts of sustainability and circularity issues has been determined as the factor that prevents organizations from adopting advanced environmental conscious practices [67-69]. Apart from the lack of awareness of circularity on organizational and managerial perspectives, public interest and reaction are 
also substantial influences on adoption of circularity. Therefore, lack of public interest and reaction to circular equipment (reusable medical devices) hold organizations back, and prevent organizations pursuing circular trends $[67,68,70]$. Therefore, lack of public perception and commitment to environmental issues is also a considerable barrier to accomplishing CE practices.

Limited Human Resources (HR) capacities also hinder the healthcare systems' implementations of CE. In this context, the following limitations to CE practices are emphaisized: resistance to change, lack of knowledge, training, expertise, and training in organizations for sustainable and circular actions [20,28,71]. In this context, another substantial barrier is limited knowledge among healthcare workers and professionals of environmental problems, resulting from insufficient HR capabilities.

Managerial barriers, such as lack of top management support and commitment about circularity, proactive strategies for environmental burden, and conflict of interest among stakeholders, also play a vital role in CE adoption. These obstacles can affect the moral judgments of employees, who may face a mismatch between their personal values and their need to comply with corporate rules [20,28,72]. Even when laws exist, lack of law enforcement and government support lead to low adherence to sustainability [73,74].

Capacity building (e.g., resources, skills, knowledge, tools, equipment, etc.) as operational and technology barriers towards CE adoption, is among the most frequently mentioned barriers in the literature [24]. In addition, the size and complexity of circularity in healthcare systems are considered as another major barrier that inhibits the improvement of green and circular healthcare systems [22]. Furthermore, the absence of suitable infrastructure is another crucial barrier for safe management of the healthcare waste disposal systems [5,16-18], and also lack of recycling options for medical devices and equipment in terms of their reusability and end-of-life cycle, causing detrimental effects on the environment. On the technical side, limited IT infrastructure and technologies in medical informatics can be determined as a barrier, i.e., lack of or insufficient technologies, poor quality of designs, standards, and codes, and inefficient performance on circular practices [75-79].

\subsection{Big Data Tools in Healthcare Applications}

The healthcare system is comprised of broad and complicated medical devices, and equipment that has a long end-of-life cycle. However, these devices have residual value at the end of their lifespan, and also have hygienic and quality risks [3]; thus, recycling of such medical devices has become a controversial issue. The problem of socially, environmentally, and economically sustainable disposal of healthcare waste has become even more complex, especially with the highly infectious waste from COVID-19 patients and healthcare professionals [5]. If medical waste is not appropriately managed and disposed of, it poses significant health threats, such as potential infection and injuries to healthcare workers [80], and results in serious damage to the environment. The increase in healthcare waste is not solely due to demographic growth. Simultaneously, the increasing usage of disposable (single-use) materials resulting from the growing number and size of hospitals has contributed dramatically to the rise of these wastes $[2,80]$. The healthcare sector has detrimental effects on the environment; thus, healthcare professionals need to be aware of the environmental cost caused in order to reduce the materials used and energy consumed $[2,81]$.

The CE concept is designed to be restorative or regenerative, as opposed to a linear economy, which absorbs limited resources, increases energy use [7], and generates waste. $\mathrm{CE}$ can be defined as an economic model that aims to reuse discarded or used products, resources, and materials as a production resource by providing protection and restoration to products and resources. It also deals with social, economic, and environmental issues at every stage of the system $[3,82]$. Therefore, the main objective of the CE is the elimination of waste by extending the product end-of-life cycle and closing the loop for the product and its components by recycling them back into the system [10]. The transition to a CE 
can provide efficiency measures by increasing cost savings, promoting more supportive environments and resilient cities, as well as improved and strengthened public health, healthcare delivery, and quality of life [83].

In the economic transition scenario for emerging economies in the healthcare sector, the adaptation and application of the CE in the I4.0 brings both opportunities and challenges [84]. Due to the inherent challenges and difficulties of healthcare data, designing and conducting big data technologies in this realm has opportunities and benefits [85]. Most healthcare systems are striving to replace outdated infrastructure and obsolete technologies with very scarce capital resources [86]. Hence, pervasive big data analytics infrastructures and computational technologies have begun to play a vital role in competitive and digital organizations, e.g., in the healthcare and pharmaceutical industry $[87,88]$. In recent years, big data has become essential in various fields, including public management, scientific research, business organizations, healthcare, manufacturing, social networking, and natural resource management [89].

Broad, diverse, and complicated computerized healthcare datasets that cannot be processed with traditional software, hardware, or data management tools are called big data in healthcare $[25,90]$. Big data refers to access, collects and store a large volume of data that is difficult to utilize using traditional data processing methods and platforms [89]. These modern big data technologies evaluate these vast amounts of data in a short time, and generate predictive models through machine learning, and statistical techniques [91]. In this context, big data analytics employs tools such as machine learning algorithms, and facilitates exploration of meaningful decisions through understanding the structure and relationships of data [92].

Machine learning tools can be described as a subset of artificial intelligence (AI), which incorporates algorithmic approaches, allowing computers to solve problems without the need for complex computer programming [93]. The integration of machine learning technologies into the healthcare sector and clinical practice has the potential to enhance healthcare quality [94]. The key areas of use of machine learning tools in the healthcare sector are clinical workflow design, training of healthcare workers, healthcare professional's performance, forecasting of the potential problems and diseases, and legal and ethical application practices [93]. Machine learning techniques can be integrated with other soft computing techniques to improve results, depending on their performance and reliability [95]. Depending upon the increasing significance of quality benchmarks in public assessments and setting reimbursement rates, it might be valuable to train machine learning algorithms to direct consumers toward clinical activities that boost quality outcomes [94]. In addition, the use of machine learning in complex health systems can support the provision of infrastructure in the field of medical informatics by receiving information from patients through electronic records.

The main description of optimization generally refers to maximization or minimization of a numerical problem by providing a function, and finding the most desirable solutions to a problem. Optimization can be adapted into all engineering regulations, as well as other fields of data mining [96]. The usefulness of maintenance optimization algorithms differs significantly based on their capability to calculate an optimal solution in the least amount of time and money [97].

Artificial neural networks can be defined as a computational approach that focuses on mathematical structures and models that have a series of connected processing elements, configuration, and function that perform parallel. Artificial intelligence offers many technological advances to healthcare services, such as cost-effective and optimal healthcare services in real-time, efficient and reliable collaboration among interdisciplinary stakeholders, and solutions for non-traditional care environments, transforming the healthcare workplace and workforce, and introducing novel and different health information systems [86].

Cloud computing is generated from the development and integration of the many independent computing approaches and technologies that refer to utility computing, ondemand services, grid computing, and self-service internet infrastructures [98]. Cloud 
computing technologies encourage and reinforce IT capabilities so that they can be accessible at all times and from every location $[99,100]$. Cloud-based clinical big data analytics offer intelligence for more reliable and sustainable health tracking [101]. Cloud computing can provide various benefits to organizations such as the minimization of technologyrelated costs (capital, operational expense saving, and labor cost) and accordingly better healthcare services [102,103], improved infrastructure and, efficient usage of resources, and increased technology standards and expertise $[100,104]$. Additionally, there are serious obstacles in medical informatics (e.g., medical data collection, analysis, management, and proposing a solution) resulting from its expense-related issues [105,106]. Furthermore, cloud computing ensures scalability, flexibility, and productivity increase in IT infrastructure, eliminates costs of energy and power. Observance with legislation, development of healthcare services, enhanced operating processes and procedures, and accurate decisionmaking capability are some important examples of cloud in healthcare practices in terms of managerial, legal, and operational perspectives [100].

Data mining is the method of observing and revealing previously discovered knowledge, patterns, and trends in datasets, which is used to create meaningful data for generating predictive models [107]. Data mining technologies comprise a number of different approaches such as data summarization, clustering, finding dependency networks, classification, evaluating changes, and specifying outliers [108]. Usage of data mining can provide proactive solutions to the many barriers and challenges. These technologies aim to eliminate risks encountered by the organization, and facilitate decision-making processes of organizations through examining their patterns and trends [107]. Data mining can assist organizations in healthcare management, customer relationship management [109], detection of fraud, and abuses to determine unusual, abnormal, and outlier patterns [108].

Social network analysis can be characterized as a social structure that consists of a group of actors or networks of people who are connected by specific characteristics [110]. Thus, social network analysis usually deals with interactions and communications among individuals and groups [111]. Rather than the assessment of a single clinical discipline, social network analysis can be used in optimizing the entire system [112,113].

Statistical techniques are subsidiary mathematical structures that extract meaningful information and insights from the data by making predictions such as modeling, machine learning, data mining [114], multiple regression, discriminant analysis, logistic regression [115], nonparametric regression, and cluster analysis [86]. The application areas of statistical techniques can be categorized as accounting and finance, health and medicine, research, manufacturing, marketing, and business [115].

\section{Methodology}

In the methodology section of the study, the first step was setting the search strings for the identification and search for the barriers, and identifying publications related to our aim. For this purpose, search queries and strings were prepared before starting the search (see Table A1).

Based on a detailed investigation of the current literature review, the determined barriers to circularity in the healthcare industry and corresponding big data solutions to these barriers are presented. After identifying the barriers, these were categorized depending on their relevance or dimensions. Big data techniques were also determined to address each of these barriers. For the implementation step of the study, 30 experts were selected as decision-makers to decide the best-worst barriers in each dimension, and among all dimensions separately via interviews. Additionally, for related big data solutions, these experts were asked to apply VIKOR as a methodology. The best-worst method and VIKOR method were adopted in this study after a detailed investigation of the methodology sections of the studies. For instance, Gupta (2018) investigated a novel hybrid methodology consisting of the best-worst method and the VIKOR method for evaluating attribute weights, and subsequently rating the numerous alternatives (airlines) in the airline sector in terms of service quality [116]. Shojaei et al. (2018) proposed an airport 
evaluation and ranking model that combines the Taguchi Loss Function, the best-worst method (BWM), and the VIKOR approach [117]. Tian et al. (2018) investigated failure mode and effects analysis (FMEA) by combining a hybrid structure, fuzzy best-worst method, relative entropy, and a fuzzy VIKOR (VIsekriterijumska optimizacija I KOmpromisno Resenje) methodology to improve the performance of traditional FMEA [118]. After obtaining results from the respindents, the calculations and validation of the results must be performed.

Therefore, regarding these aforementioned barriers and relevant big data solutions discussed in the previous section of this study, the proposed barriers and big data solutions need to be validated through expert opinions. In this context, a group of seven experts, consisting of two professors from the faculty of medicine (25 and 20 years of experience, respectively), three industry experts, managing directors of well-known hospitals $(14,17$, and 11 years of experience), and two governmental experts from the Ministry of Health (14 and 12 years of experience). They met to discuss the predetermined barriers and related big data solutions. Interviews were held with these industry experts and academics to discuss the proposed barriers to circularity in the healthcare industry. Although independent opinions of experts were based on the importance of specific barriers, we selected the most frequently mentioned barriers that play a major role in the adoption of CE initiatives in the healthcare sector.

After the validation process, the healthcare barriers to circularity were matched with Big Data solutions. Figure 1 displays the all-inclusive flow of current research work.

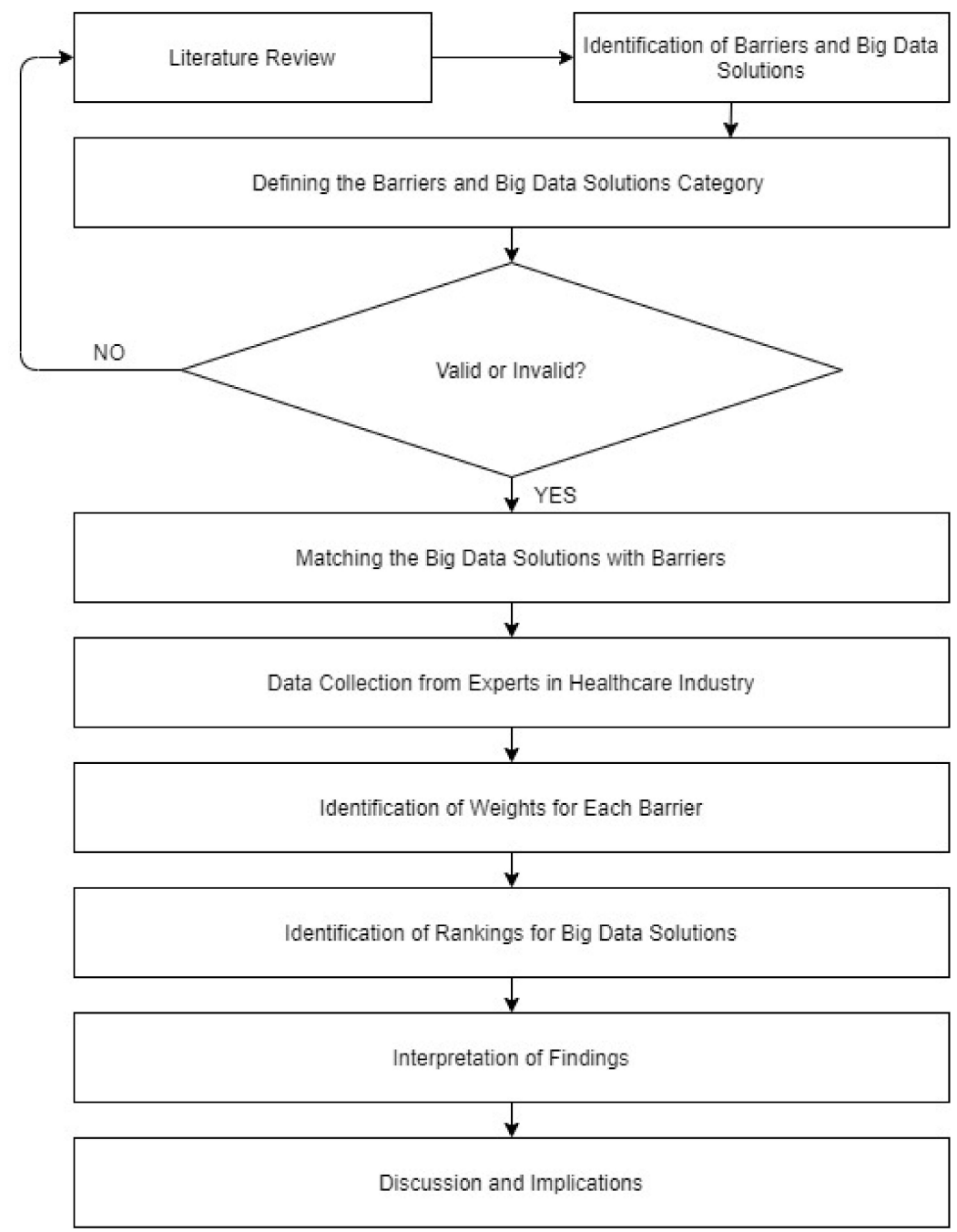

Figure 1. The overall flow of current research work. 
The fuzzy best-worst method was adopted to this study to calculate the relevant barrier and sub-barrier weights, and the fuzzy VIKOR method was used for ranking the big data analytics solutions for predetermined barriers.

The next section introduces the fuzzy set theory, the fuzzy best-worst method, and the fuzzy VIKOR method.

\subsection{Fuzzy Set Theory}

The process of decision-making involves some vagueness as a result of the ambiguity in the decision-making process. In attempt to deal with uncertainty, Zadeh [119] developed fuzzy set theory. This idea assists decision-makers in minimizing the subjectivity and ambiguity of human-related factors. A fuzzy set is referred to as a collection of objects with a range of grades.

\subsection{Fuzzy Best-Worst Method}

The best-worst method (BWM) is a comparatively new method, which was introduced by Rezaei [120]. As BWM is a vector-based method, it requires fewer pairwise comparisons compared to AHP or ANP, and the solution may be reached in a shorter time and with less complication. Furthermore, BWM comprises a mathematical model.

For weighing the criteria, BWM has five steps to follow.

Step 1: A criterion set, which is $\left\{c_{1}, c_{2}, \ldots, c_{n}\right\}$ is defined;

Step 2: The most important $\left(c_{B}\right)$, and least important $\left(c_{W}\right)$ criteria are identified;

Step 3: The most important criterion is compared with each of the other criteria. The best-to-others vector is identified by comparing the most important criterion with each of the other criteria. The best-to-others vector can be expressed as $\widetilde{A}_{B}=\left(\widetilde{a}_{B 1}, \widetilde{a}_{B 2}, \ldots, \widetilde{a}_{B n}\right)$. $\tilde{a}_{B j}$ represents the fuzzy force of the most important criterion over criterion $j$. For example, $\widetilde{a}_{B B}=(1,1,1)$;

Step 4: Each of these criterion needs to be compared with the least important criterion. The others-to-worst vector is identified by comparing each criterion with the least important one. The others-to-worst vector can be denoted as $\widetilde{A}_{W}=\left(\widetilde{a}_{1 W}, \widetilde{a}_{2 W}, \ldots, \widetilde{a}_{n W}\right)^{T}$. $\widetilde{a}_{i W}$ rerepresents the criterion's fuzzy force $j$ over the least important criterion. For instance, $\widetilde{a}_{W W}=(1,1,1)$

Step 5: The optimal or ideal fuzzy weights $\left(\widetilde{w_{1}^{*}}, \widetilde{w_{2}^{*}}, \ldots, \widetilde{w_{n}^{*}}\right)$ are calculated. The optimal fuzzy weights are $\widetilde{w}_{B} / \widetilde{w}_{j}=\widetilde{a}_{B j}$ and $\widetilde{w}_{j} / \widetilde{w}_{W}=\widetilde{a}_{j W}$ for each pair. The maximum absolute differences are determined as $\left|\frac{\widetilde{w}_{B}}{\widetilde{w}_{j}}-\widetilde{a}_{B j}\right|$ and $\left|\frac{\widetilde{w}_{j}}{\widetilde{w}_{W}}-\widetilde{a}_{j W}\right|$ for all $j$. All $j$ values need to be formulated as a minimization model. $\widetilde{w}_{B}, \widetilde{w}_{W}$, and $\widetilde{w}_{j}$ are triangular fuzzy numbers.

The mathematical model was developed as follows:

$$
\begin{gathered}
\text { Minimize } \max \left\{\left|\frac{\widetilde{w}_{B}}{\widetilde{w}_{j}}-\widetilde{a}_{B j}\right|,\left|\frac{\widetilde{w}_{j}}{w_{W}}-\widetilde{a}_{j W}\right|\right\} \\
\text { s.t. }\left\{\begin{array}{c}
\sum_{j=1}^{n} R\left(\widetilde{w}_{j}\right)=1 \\
l_{j}^{w} \leq m_{j}^{w} \leq u_{j}^{w} \\
l_{j}^{w} \geq 0 \\
j=1,2, \ldots, n
\end{array}\right. \\
\widetilde{w}_{B}=\left(l_{B}^{w}, m_{B}^{w}, u_{B}^{w}\right), \widetilde{w}_{W}=\left(l_{W}^{w}, m_{W}^{w}, u_{W}^{w}\right), \widetilde{w}_{j}=\left(l_{j}^{w}, m_{j}^{w}, u_{j}^{w}\right),
\end{gathered}
$$

This mathematical model can be written as follows: 
Minimize $\widetilde{\zeta}$

$$
\text { s.t. }\left\{\begin{array}{c}
\sum_{j=1}^{n} R\left(\widetilde{w}_{j}\right)=1 \\
l_{j}^{w} \leq m_{j}^{w} \leq u_{j}^{w} \\
\left|\frac{\widetilde{w}_{B}}{\widetilde{w}_{j}}-\widetilde{a}_{B j}\right| \leq \widetilde{\xi} \\
\left|\frac{\widetilde{w}_{j}}{\widetilde{w}_{W}}-\widetilde{a}_{j W}\right| \leq \widetilde{\xi} \\
l_{j}^{w} \geq 0 \\
j=1,2, \ldots, n \\
\widetilde{\xi}=\left(l^{\xi}, m^{\xi}, u^{\xi}\right) .
\end{array}\right.
$$

It can be supposed that $\widetilde{\zeta}^{*}=\left(k^{*}, k^{*}, k^{*}\right)$ and $k^{*} \leq l^{\xi}$ when $l^{\xi} \leq m^{\xi} \leq u^{\xi}$. The model can then be formulated as:

Minimize $\widetilde{\xi}$

$$
\text { s.t. }\left\{\begin{array}{c}
\sum_{j=1}^{n} R\left(\widetilde{w}_{j}\right)=1 \\
l_{j}^{w} \leq m_{j}^{w} \leq u_{j}^{w} \\
\left|\frac{l_{B}^{w}, m_{B}^{w}, u_{B}^{w}}{\left(l_{j}^{w}, m_{j}^{w}, u_{j}^{w}\right)}-\left(l_{B j}, m_{B j}, u_{B j}\right)\right| \leq\left(k^{*}, k^{*}, k^{*}\right) \\
\left|\frac{\left(l_{j}^{w}, m_{j}^{w}, u_{j}^{w}\right)}{\left(l_{W}^{w}, m_{W}^{w}, u_{W}^{w}\right)}-\left(l_{j W}, m_{j W}, u_{j W}\right)\right| \leq\left(k^{*}, k^{*}, k^{*}\right) \\
l_{j}^{w} \geq 0 \\
j=1,2, \ldots, n
\end{array}\right.
$$

The optimal fuzzy weights, $\left(w_{1}^{*}, w_{2}^{*}, \ldots, w_{n}^{*}\right)$ can be obtained.

\subsection{Fuzzy VIKOR}

The VlseKriterijumska Optimizacija I Kompromisno Resenje (VIKOR) method was introduced by Opricovic [121], and Opricovic and Tzeng [122]. The main aim of the VIKOR method is identified as selecting the best alternative among others.

Opricovic [123] highlighted the steps of fuzzy VIKOR as the following:

Step 1: The fuzzy best and worst values are identified. The fuzzy best value $\tilde{f}_{j}^{*}=\left(l_{j}^{*}, m_{j}^{*}, r_{j}^{*}\right)$ and fuzzy worst value $\tilde{f}_{j}^{-}=\left(l_{j}^{-}, m_{j}^{-}, r_{j}^{-*}\right)$ are found as follows:

$$
\begin{aligned}
& \tilde{f}_{j}^{*}=\max _{i} \widetilde{x}_{i j} \\
& \tilde{f}_{j}^{-}=\min _{i} \widetilde{x}_{i j}
\end{aligned}
$$

Step 2: The fuzzy difference $\left(\widetilde{d}_{i j}\right)$ is found as follows:

$$
\widetilde{d}_{i j}=\left(\widetilde{f}_{j}^{*}-\widetilde{x}_{i j}\right) /\left(r_{j}^{*}-l_{j}^{-}\right)
$$

Step 3: The separation values $\widetilde{S}_{i}$, and $\widetilde{R}_{i}$ of $i^{\text {th }}$ alternative are found as follows:

$$
\begin{gathered}
\widetilde{S}_{i}=\sum_{j=1}^{m} \widetilde{w}_{j} \times \widetilde{d}_{i j} \\
\widetilde{R}_{i}=\max _{j} \widetilde{w}_{j} \times \widetilde{d}_{i j}
\end{gathered}
$$


where $\widetilde{S}_{i}=\left(S_{i}^{l}, S_{i}^{m}, S_{i}^{r}\right)$ is a weighted score of the sum in terms of the separation value of $i$ th option from $f_{j}^{*}$. In a similar way, $\widetilde{R}_{i}=\left(R_{i}^{l}, R_{i}^{m}, R_{i}^{r}\right)$ determines the separation value of $i$ th alternative from $f_{j}^{-}$. $w_{i}$ is the respective criterion's weight, $C_{j}$;

Step 4: $Q_{i}$ value is found: The value of $\widetilde{Q}_{i}=\left(l_{i}, m, r_{i}\right)$ is found by:

$$
\widetilde{Q}_{i}=v\left[\left(\widetilde{S}_{i}-\widetilde{S}^{*}\right) /\left(S^{-r}-S^{* l}\right)\right]+(1-v)\left[\frac{\widetilde{R}_{i}-\widetilde{R}^{*}}{R^{-r}-R^{* l}}\right]
$$

where $\widetilde{S}^{*}=\min _{i} \widetilde{S}_{i}, \widetilde{S}^{-r}=\max _{i} \widetilde{S}_{i}^{r}, \widetilde{R}^{*}=\min _{i} \widetilde{R}_{i}$, and $\widetilde{R}^{-r}=\min _{i} \widetilde{R}_{i} . v$ represents the weight for the maximum group utility, whereas $(1-v)$ shows the weight for individual regret. Then, $\widetilde{S}_{i}, \widetilde{R}_{i}$, and $\widetilde{Q}_{i}$ values are defuzzified to reveal the crisp values. The crisp $S_{i}$, $R_{i}$, and $Q_{i}$ values are sorted escalatory order. The best alternative is identified through the corresponding minimum $Q_{i}$ value when the following two conditions are satisfied:

1. $Q\left(A^{(2)}\right)-Q\left(A^{(1)}\right) \geq D Q$, where $A^{(1)}$ and $A^{(2)}$ are the first- and second-best alternatives, respectively;

2. $A^{(1)}$ must also be found as the best alternative respecting $S_{i}$, and $R_{i}$ values [124].

\section{Case Study}

This study mainly addresses the implementation phase, conducted in five chain hospitals located in Izmir, Turkey. However, it is important to note that these selected hospitals were chain hospitals, with branches operating in various regions of Turkey. Thus, the results of the study may be generalizable beyond the Izmir region.The major purpose is to determine the barriers of circular economy for the healthcare industry, and propose big data solutions to overcome each barrier.

The pairwise comparisons are conducted with 30 experts with different backgrounds. Table 2 displayed participant's information during the study.

Table 2. Information about Participants.

\begin{tabular}{|c|c|c|c|c|c|}
\hline Experts & $\begin{array}{l}\text { Position of the } \\
\text { Participants }\end{array}$ & $\begin{array}{l}\text { Years of Work Experiences } \\
\text { (in Total) }\end{array}$ & Experts & $\begin{array}{l}\text { Position of the } \\
\text { Participants }\end{array}$ & $\begin{array}{l}\text { Years of Work Experiences } \\
\text { (in Total) }\end{array}$ \\
\hline 1 & Hospital Manager & 21 & 16 & Sustainability Expert & 11 \\
\hline 2 & Hospital Manager & 18 & 17 & Sustainability Expert & 9 \\
\hline 3 & Hospital Manager & 14 & 18 & Sustainability Expert & 10 \\
\hline 4 & Hospital Manager & 17 & 19 & Circularity Expert & 8 \\
\hline 5 & Hospital Manager & 18 & 20 & Circularity Expert & 9 \\
\hline 6 & Head Doctor & 24 & 21 & $\begin{array}{c}\text { Information Technology } \\
\text { Expert }\end{array}$ & 15 \\
\hline 7 & Head Doctor & 20 & 22 & $\begin{array}{l}\text { Information Technology } \\
\text { Expert }\end{array}$ & 13 \\
\hline 8 & Head Doctor & 19 & 23 & $\begin{array}{c}\text { Information Technology } \\
\text { Expert }\end{array}$ & 9 \\
\hline 9 & Head Doctor & 23 & 24 & $\begin{array}{c}\text { Information Technology } \\
\text { Expert }\end{array}$ & 14 \\
\hline 10 & Head Doctor & 27 & 25 & $\begin{array}{c}\text { Information Technology } \\
\text { Expert }\end{array}$ & 18 \\
\hline 11 & Supply Chain Manager & 13 & 26 & Ministry of Health Personnel & 11 \\
\hline 12 & Supply Chain Manager & 15 & 27 & Ministry of Health Personnel & 12 \\
\hline 13 & Supply Chain Manager & 9 & 28 & Ministry of Health Personnel & 9 \\
\hline 14 & Supply Chain Manager & 15 & 29 & Ministry of Health Personnel & 14 \\
\hline 15 & Supply Chain Manager & 14 & 30 & Ministry of Health Personnel & 7 \\
\hline
\end{tabular}


The proposed framework can be used for generic purposes where circular economy barriers in healthcare industry are studied; however, the findings are unique and cannot be generalized.

Table 3 demonstrates the best and worst criteria for each main criterion.

Table 3. The best and worst criteria for each main criterion.

\begin{tabular}{|c|c|c|}
\hline Main Criteria & Best Criteria & Worst Criteria \\
\hline Economic and Financial & $\begin{array}{l}\text { High cost requirement for circular technologies } \\
\text { and implementations }\end{array}$ & Lack of demand for eco-friendly medical supplies \\
\hline Policy & $\begin{array}{c}\text { Unfavorable government legislation and execution on } \\
\text { circular healthcare }\end{array}$ & Lack of favorable policies for using technology \\
\hline Organizational & Lack of organizational readiness for CE activities & $\begin{array}{l}\text { Current institutional misconceptions } \\
\text { about sustainability }\end{array}$ \\
\hline Environmental & Lack of safe management of medical waste in healthcare & Single-use medical devices and supplies \\
\hline Social & Lack of awareness about circularity & Lack of public interest and reaction \\
\hline Human Resources & $\begin{array}{l}\text { Lack of know-how, training, and expertise training for } \\
\text { CE activities }\end{array}$ & Resistance to change \\
\hline Managerial & $\begin{array}{l}\text { Lack of the top management support and commitment } \\
\text { about circularity }\end{array}$ & Proactive strategies for environmental burden \\
\hline Operational and Technology & Complexity of circularity in healthcare systems & $\begin{array}{l}\text { Limited IT infrastructure and technologies in } \\
\text { medical informatics }\end{array}$ \\
\hline
\end{tabular}

The weights of the main barriers were found as the step-by-step application of fuzzy BWM, and can be shown in Table 4 .

Table 4. The Weights of Main Barriers.

\begin{tabular}{cc}
\hline Main Barriers & Weights \\
\hline Economic and Financial & 0.275 \\
\hline Policy & 0.203 \\
\hline Organizational & 0.087 \\
\hline Environmental & 0.111 \\
\hline Social & 0.056 \\
\hline Human Resources & 0.073 \\
\hline Managerial & 0.079 \\
\hline Operational and Technology & 0.117 \\
\hline
\end{tabular}

According to the results in Table 4, economic and financial barriers were classified as the most substantial barrier to circularity with 0.275 weight. Policy barriers, operational barriers, and environmental barriers were also found as the other substantial barriers.

The weights of the sub-barriers within their own cluster, and the overall individual weights can be shown in Table 5 .

Table 5. Sub-Barrier Weights.

\begin{tabular}{ccccc}
\hline Barriers & $\begin{array}{c}\text { Weights of } \\
\text { Barriers }\end{array}$ & Sub-Barriers & $\begin{array}{c}\text { Weights of } \\
\text { Sub-Barriers }\end{array}$ & $\begin{array}{c}\text { Overall Individual } \\
\text { Weights }\end{array}$ \\
\hline & & $\begin{array}{c}\text { High cost requirement for circular technologies } \\
\text { and implementations }\end{array}$ & 0.477 & 0.131 \\
\cline { 3 - 5 } $\begin{array}{c}\text { Economic and } \\
\text { Financial }\end{array}$ & 0.275 & $\begin{array}{c}\text { Lack of financial capabilities and resources on } \\
\text { environmental investments }\end{array}$ & 0.252 & 0.069 \\
\cline { 3 - 5 } & & $\begin{array}{c}\text { Challenges in identifying the economic benefits of } \\
\text { environmental investments }\end{array}$ & 0.166 & 0.045 \\
\cline { 2 - 5 } & & Lack of demand for eco-friendly medical supplies & 0.106 & 0.029 \\
\hline
\end{tabular}


Table 5. Cont.

\begin{tabular}{|c|c|c|c|c|}
\hline Barriers & $\begin{array}{l}\text { Weights of } \\
\text { Barriers }\end{array}$ & Sub-Barriers & $\begin{array}{l}\text { Weights of } \\
\text { Sub-Barriers }\end{array}$ & $\begin{array}{l}\text { Overall Individual } \\
\text { Weights }\end{array}$ \\
\hline \multirow{3}{*}{ Policy } & \multirow{3}{*}{0.203} & Lack of circular policies, incentives, and regulations in healthcare & 0.310 & 0.063 \\
\hline & & Lack of favorable policies for using technology & 0.150 & 0.030 \\
\hline & & $\begin{array}{l}\text { Unfavorable government legislation and execution on } \\
\text { circular healthcare }\end{array}$ & 0.540 & 0.110 \\
\hline \multirow{5}{*}{ Organizational } & \multirow{5}{*}{0.087} & Poor organizational design for CE principles & 0.153 & 0.013 \\
\hline & & Current institutional misconceptions about sustainability & 0.095 & 0.008 \\
\hline & & Inconsistency of healthcare cultures and values with CE principles & 0.230 & 0.020 \\
\hline & & Lack of established standards for CE activities in healthcare & 0.137 & 0.012 \\
\hline & & Lack of organizational readiness for CE activities & 0.385 & 0.033 \\
\hline \multirow{3}{*}{ Environmental } & \multirow{3}{*}{0.111} & Lack of safe management of medical waste in healthcare & 0.601 & 0.066 \\
\hline & & Lack of environmental management & 0.246 & 0.027 \\
\hline & & Single-use medical devices and supplies & 0.153 & 0.017 \\
\hline \multirow{3}{*}{ Social } & \multirow{3}{*}{0.056} & Lack of public perception and commitment to environmental issues & 0.192 & 0.011 \\
\hline & & Lack of awareness about circularity & 0.660 & 0.037 \\
\hline & & Lack of public interest and reaction & 0.147 & 0.008 \\
\hline \multirow{4}{*}{ Human Resources } & \multirow{4}{*}{0.073} & Resistance to change & 0.100 & 0.007 \\
\hline & & $\begin{array}{l}\text { Limited knowledge-base on environmental problems among } \\
\text { employees for CE activities }\end{array}$ & 0.205 & 0.015 \\
\hline & & Lack of know-how, training, and expertise training for CE activities & 0.540 & 0.039 \\
\hline & & Limited HR capacity for CE activities & 0.154 & 0.011 \\
\hline \multirow{3}{*}{ Managerial } & \multirow{3}{*}{0.079} & $\begin{array}{l}\text { Lack of the top management support and commitment about } \\
\text { circularity }\end{array}$ & 0.640 & 0.051 \\
\hline & & Proactive strategies for environmental burden & 0.167 & 0.013 \\
\hline & & Conflict of interest among stakeholders & 0.192 & 0.015 \\
\hline \multirow{6}{*}{$\begin{array}{l}\text { Operational and } \\
\text { Technology }\end{array}$} & \multirow{6}{*}{0.117} & $\begin{array}{l}\text { Challenges in identifying the impacts of environmental practices to } \\
\text { clinical processes }\end{array}$ & 0.133 & 0.016 \\
\hline & & Capacity building & 0.122 & 0.014 \\
\hline & & Complexity of circularity in healthcare systems & 0.415 & 0.049 \\
\hline & & Poor infrastructure & 0.178 & 0.021 \\
\hline & & Lack of recycling options in medical supplies & 0.094 & 0.011 \\
\hline & & Limited IT infrastructure and technologies in medical informatics & 0.058 & 0.007 \\
\hline
\end{tabular}

Accordingly, "High cost requirement for circular technologies and implementations" was found as the most important barrier, with a weight of 0.131 . Other important barriers were found to be "Unfavorable government legislation and execution on circular healthcare", "Lack of financial capabilities and resources on environmental investments", "Lack of safe management of medical waste in healthcare", "Lack of circular policies, incentives, and regulations in healthcare", "Lack of the top management support and commitment about circularity", "Complexity of circularity in healthcare systems", and "Challenges in identifying the economic benefits of environmental investments".

After the implementation of the best-morst method, the next step was to identify ways to overcome these barriers. In this context, the VIKOR method was applied in the study in order to determine which big data-enabled technologies and solutions would appropriate for a smoother $\mathrm{CE}$ transition in the healthcare sector. Therefore, to overcome the barriers to $\mathrm{CE}$ initiatives, the experts investigated related big data technologies, including statistical techniques, cloud computing, data mining, artificial neural network, optimization, machine learning, and social network analysis. 
According to the VIKOR application, Table 6 presents the rankings of the Big Data solutions for overcoming the barriers connected with a $\mathrm{CE}$ in healthcare industry. The ranking for the barriers is calculated via fuzzy VIKOR method.

Table 6. Rankings of Big Data Solutions.

\begin{tabular}{ccc}
\hline Rankings & Solutions & $\mathbf{Q}_{\mathbf{i}}$ \\
\hline 1 & Cloud Computing & 0.065 \\
\hline 2 & Artificial Neural Network & 0.313 \\
\hline 3 & Optimization & 0.455 \\
\hline 4 & Data Mining & 0.496 \\
\hline 5 & Machine Learning & 0.551 \\
\hline 6 & Statistical Techniques & 0.749 \\
\hline 7 & Social Network Analysis & 0.882 \\
\hline
\end{tabular}

Accordingly, cloud computing was found as the most important solution of big data to overcome the barriers to $\mathrm{CE}$ in healthcare industry. Other important solutions were found to be artificial neural networks, optimization, and data mining.

\section{Discussion of Findings}

The results suggest that 8 of 31 barriers were found as important: namely "High cost requirement for circular technologies and implementations", "Unfavorable government legislation and execution on circular healthcare", "Lack of financial capabilities and resources on environmental investments", "Lack of safe management of medical waste in healthcare", "Lack of circular policies, incentives, and regulations in healthcare", "Lack of the top management support and commitment about circularity", "Complexity of circularity in healthcare systems", and "Challenges in identifying the economic benefits of environmental investments". These combined have a total nearly $58 \%$ of importance weight. Three were determined among economic and financial barriers, two were policy barriers, and one each was environmental, managerial, and operational and technology barriers. This is not a surprise, as financial constraints were considered the most important obstacles in healthcare sector. In addition, policy barriers were directly related to governmental and legal issues, which were externally determined by governmental institutions; therefore, it is natural to find policy barriers as important.

Cloud computing was found as the most important big data solution to overcome the barriers to $C E$ in the healthcare industry. In addition to that artificial neural networks, optimization, and data mining were suggested as other important solutions that can be adopted for addressing CE barriers and overcoming them. This was expected, as cloud computing can provide subsequent benefits to organizations, such as the minimization of cost for technology investments (capital, operational expense saving, and labor cost) and, accordingly, better healthcare services [102,103], overcoming poor infrastructure, insufficient resources, and lack of expertise and technology [100,104].

\subsection{Managerial Implications}

According to the results of the study, it can be deduced that insufficient or nonexistent infrastructure investments of hospitals result from the high-cost of adopting and implementing these circular technologies. This result shows that hospitals need to take a more proactive role in improving the healthcare infrastructure, as it allows for rapid adaptation to continuously changing environments, which improves response times during pandemics [125]. In order to propose a solution for healthcare organizations with insufficient resources to invest in circular technologies and build infrastructure, cloud technologies are appropriate due to their infrastructure and different platforms, allowing users to install and run their applications in virtual servers based on their specific requirements [104]. 
Additionally, the lack of know-how, training, and expertise barrier is a substantial obstacle to the effective implementation of the circular activities, due to the recruitment, training, expertise, and knowledge of the medical staff involved. Thus, these processes require digital capabilities, skills, and in-job training, which can be used to increase the medical staff's capacities. The artificial neural network (ANN) model could be valuable in the recruitment processes to determine and predict the staff's expertise and performancerelated information, and applied to in-job training to increase the capability and capacity of the workers. In addition, the results show that stakeholder management should be improved, as the healthcare industry's multi-stakeholder structure needs to be digitally managed. The inimitableness of the healthcare sector, which has a substantial effect on the design of SCs, derives from its features such as the complexity of circular technologies, and the multiple tiers of stakeholders in the healthcare supply chain [60]. In this context, it is necessary to examine entire health processes and tiers in detail to reveal all the complexities of the healthcare supply chain for this transition. Process reengineering, data mining, and machine learning can be adapted to reveal the complexities of this barrier.

\subsection{Policy Implications}

Policy barriers are one of the two most important barriers, according to the global weights in all dimensions. Thus, policy implications have a causal relationship with the other barriers, and solutions to these barriers might provide effective solutions to the others. For instance, the underlying reason for most barriers is the lack of education and sufficient incentives. It is therefore vitally important to provide government legislation for education about circular practices. The competence to use digital technologies effectively needs to be a key focus in the healthcare sector. Students' digital skills, analytical thinking, and decision-making skills are becoming incrementally important, and are highly related with the rapid transition and adaptability to the ever-changing conditions. This solution involves incorporating artificial intelligence and data mining in digital skills education. Furthermore, the optimization tool of big data can be beneficial in analytical thinking. Finally, optimization and statistical techniques can be adapted to the purpose of decisionmaking processes. Additionally, focusing on education can play a key role in reducing the deficiencies in know-how, training, and expertise. Government incentives are another crucial element due to the high cost of in-job training required for the development of workers. These cost-related investments must be encouraged and supported by the government. Data mining and machine learning tools can be used to reduce the financial burden of these requirements.

\subsection{Theoretical Implications}

The systems approach can be suitable for the healthcare sector, which is composed of multiple tiers and stakeholders. A systems approach can be described as a way of thinking in terms of connectedness, interactions, and context towards sustainability implementations, which can be a more valuable viewpoint than other theoretical approaches. A systems methodology entails gathering together experts from the appropriate disciplines into a team, which then uses a systematic framework to deliver a system, operating from needs to specifications and concept to implementation [126].

\section{Conclusions}

In the healthcare sector, the conservation of the natural resources is hindered by insufficient infrastructure for managing residual waste resulting from the usage of singleuse medical materials, and by the environmental burden of excessive energy use. In addition, the COVID-19 pandemic has increased the challenges to the already strained healthcare sector. Additionally, economic crisis in the healthcare sector has had a huge impact, urging a faster transition to environmental sustainability, and the adoption of business strategies to eliminate residual waste and lower costs [127]. In this context, the circularity and sustainability concepts have become a must for healthcare to meliorate the 
sector's negative impacts on the environment. Therefore, this study aims to identify the circular-related barriers in the healthcare sector and propose solutions.

In order to propose solutions to challenges, a detailed examination of the existing literature on healthcare was conducted, and it was understood that big data technologies and tools should be applied to the healthcare supply chain. Additionally, it was found that the connection between circularity (CE) and big data was a gap in the current literature hindering circularity practices in healthcare. Therefore, this problem requires special attention and solution suggestions. Usage of big data tools can provide social, economic, and environmental opportunities, and innovative solutions for circularity practices in the healthcare sector, especially during a pandemic, in which medical waste are ever increasing. In the health sector, waste management and recycling activities are key in reducing costs and, thus, enabling better patient care [61]. In this context, the main contribution of this study is the proposal for a big data-enabled framework for CE adoption in healthcare.

A detailed examination of the existing literature in the healthcare sector allowed the identification of barriers to $C E$ transition. As a result, determined 31 sub-barriers were categorized under eight main dimensions. Fuzzy set theory was also incorporated into the study in order to deal with subjective and vague human decisions. For obtaining ranking and weights to these barriers, the fuzzy best-worst method was applied to find the best and worst main and sub-barriers. After this step, the fuzzy VIKOR method was used to rank the alternatives.

Accordingly, "High cost requirement for circular technologies and implementations" was found as the most important barrier. Other important barriers were "Unfavorable government legislation and execution on circular healthcare", "Lack of financial capabilities and resources on environmental investments", "Lack of safe management of medical waste in healthcare", "Lack of circular policies, incentives, and regulations in healthcare", "Lack of the top management support and commitment about circularity", "Complexity of circularity in healthcare systems", and "Challenges in identifying the economic benefits of environmental investments". Cloud computing was found as the most important big data solution to overcome the barriers to $\mathrm{CE}$ in healthcare industry, and other important solutions were artificial neural networks, optimization, and data mining.

This study addresses a case study implementation in Turkey, which is a developing economy, thus it can be identified as a limitation of this study because of the generalizability of the results. When the implementation is applied to a developed country, different results may emerge. Another limitation is that the data used includes subjective judgments.

Future research might focus on the implementation of this proposed framework in other developing and emerging economies. Additionally, to better understand the implications of the framework, further studies could focus on determining the cause and effect relationship among barriers to $\mathrm{CE}$ and analytics of big data.

Author Contributions: Conceptualization, Y.K. and Ç.L.; Methodology, Y.K., M.S., A.K. and S.L.; Validation, Y.K., M.S. and C.T.; Formal Analysis, Ç.L., A.K. and S.L.; Investigation, Ç.L. and C.T.; Resources, Y.K., Ç.L. and M.S.; Writing—Original Draft Preparation, Ç.L.; Writing—Review \& Editing, C.T. All authors have read and agreed to the published version of the manuscript.

Funding: This research received no external funding.

Institutional Review Board Statement: Not applicable.

Informed Consent Statement: Not applicable.

Data Availability Statement: No new data was created or analyzed in this study. Data sharing is not applicable to this article.

Conflicts of Interest: Authors state that there are no confict of interests to declare. 


\section{Appendix A}

Table A1. The Search Strings for Examination of Barriers.

\begin{tabular}{|c|c|}
\hline Healthcare & ("healthcare sector" OR “medical" OR “health management" OR "public health" OR “health") \\
\hline \multicolumn{2}{|r|}{ AND } \\
\hline Big Data Techniques & $\begin{array}{l}\text { "machine learning tools" OR "cloud computing" OR "artificial neural network" OR "optimization" OR } \\
\text { "data mining" OR "statistical techniques" OR "social network analysis" OR "A/B testing" OR “data } \\
\text { fusion and data integration" OR "natural language processing" OR "statistics" OR "association rule } \\
\text { learning" OR "sentiment analysis" OR "genetic algorithms" OR “classification tree analysis" OR } \\
\text { "regression analysis" OR "predictive modeling" OR "feature engineering") }\end{array}$ \\
\hline
\end{tabular}

AND

("circular economy" OR "green economy" OR "closed-loop economy" OR "circularity" OR

Circular Economy "sustainability" OR "single-use medical materials" OR "medical waste" OR "greenhouse-gas emissions" OR "recycle" OR "reuse" OR "refuse" OR "reduce" OR "refurbish" OR "remanufacture" OR "repair" OR "recovery" OR "repurpose")

\section{AND}

\section{References}

1. Barbero, S.; Pallaro, A. Systemic Design for Sustainable Healthcare. Des. J. 2017, 20 (Suppl. 1), S2473-S2485. [CrossRef]

2. Van Straten, B.; Dankelman, J.; Van der Eijk, A.; Horeman, T. A Circular Healthcare Economy; a feasibility study to reduce surgical stainless steel waste. Sustain. Prod. Consum. 2021, 27, 169-175. [CrossRef]

3. Van Boerdonk, P.J.M.; Krikke, H.R.; Lambrechts, W. New business models in circular economy: A multiple case study into touch points creating customer values in health care. J. Clean. Prod. 2021, 282, 125375. [CrossRef]

4. Ajao, B.M. Circularity in Wastewater Treatment Plants: Drivers and Barriers to the Commercialisation of Bioplastics from Wastewater. Master's Thesis, University of Twente, Enschede, The Netherlands, 2020.

5. Chauhan, A.; Jakhar, S.K.; Chauhan, C. The interplay of circular economy with industry 4.0 enabled smart city drivers of healthcare waste disposal. J. Clean. Prod. 2021, 279, 123854. [CrossRef]

6. Ivanov, D. Predicting the impacts of epidemic outbreaks on global supply chains: A simulation-based analysis on the coronavirus outbreak (COVID-19/SARS-CoV-2) case. Transp. Res. Part E Logist. Transp. Rev. 2020, 136, 101922. [CrossRef]

7. MacNeill, A.J.; Hopf, H.; Khanuja, A.; Alizamir, S.; Bilec, M.; Eckelman, M.J.; Hernandez, L.; McGain, F.; Simonsen, K.; Thiel, C.; et al. Transforming the Medical Device Industry: Road Map To A Circular Economy: Study examines a medical device industry transformation. Health Aff. 2020, 39, 2088-2097. [CrossRef]

8. Nandi, S.; Sarkis, J.; Hervani, A.A.; Helms, M.M. Redesigning supply chains using blockchain-enabled circular economy and COVID-19 experiences. Sustain. Prod. Consum. 2021, 27, 10-22. [CrossRef]

9. Wuyts, W.; Marin, J.; Brusselaers, J.; Vrancken, K. Circular economy as a COVID-19 cure? Resour. Conserv. Recycl. 2020, 162, 105016. [CrossRef] [PubMed]

10. Kane, G.M.; Bakker, C.A.; Balkenende, A.R. Towards design strategies for circular medical products. Resour. Conserv. Recycl. 2018, 135, 38-47. [CrossRef]

11. Den Hollander, M.C.; Bakker, C.A.; Hultink, E.J. Product design in a circular economy: Development of a typology of key concepts and terms. J. Ind. Ecol. 2017, 21, 517-525. [CrossRef]

12. Queiroz, M.M.; Ivanov, D.; Dolgui, A.; Wamba, S.F. Impacts of epidemic outbreaks on supply chains: Mapping a research agenda amid the COVID-19 pandemic through a structured literature review. Ann. Oper. Res. 2020, 16, 1-38. [CrossRef]

13. Fedotkina, O.; Gorbashko, E.; Vatolkina, N. Circular economy in Russia: Drivers and barriers for waste management development. Sustainability 2019, 11, 5837. [CrossRef]

14. Lin, R.; Ye, Z.; Wang, H.; Wu, B. Chronic diseases and health monitoring big data: A survey. IEEE Rev. Biomed. Eng. 2018, 11, 275-288. [CrossRef]

15. Mehta, N.; Pandit, A. Concurrence of big data analytics and healthcare: A systematic review. Int. J. Med. Inform. 2018, 114, 57-65. [CrossRef]

16. Zhang, A.; Venkatesh, V.G.; Liu, Y.; Wan, M.; Qu, T.; Huisingh, D. Barriers to smart waste management for a circular economy in China. J. Clean. Prod. 2019, 240, 118198. [CrossRef]

17. Campion, N.; Thiel, C.L.; Woods, N.C.; Swanzy, L.; Landis, A.E.; Bilec, M.M. Sustainable healthcare and environmental life-cycle impacts of disposable supplies: A focus on disposable custom packs. J. Clean. Prod. 2015, 94, 46-55. [CrossRef]

18. Caniato, M.; Tudor, T.; Vaccari, M. International governance structures for health-care waste management: A systematic review of scientific literature. J. Environ. Manag. 2015, 153, 93-107. [CrossRef] [PubMed] 
19. Vejaratnam, N.; Mohamad, Z.F.; Chenayah, S. A systematic review of barriers impeding the implementation of government green procurement. J. Public Procure. 2020, 20, 451-471. [CrossRef]

20. Hussain, M.; Khan, M.; Ajmal, M.; Sheikh, K.S.; Ahamat, A. A multi-stakeholders view of the barriers of social sustainability in healthcare supply chains. Sustain. Account. Manag. Policy J. 2019, 10, 290-313. [CrossRef]

21. Khan, M.; Ajmal, M.; Hussain, M.; Helo, P. Barriers to social sustainability in the health-care industry in the UAE. Int. J. Organ. Anal. 2018, 26, 450-469. [CrossRef]

22. Zadeh, R.S.; Xuan, X.; Shepley, M.M. Sustainable healthcare design: Existing challenges and future directions for an environmental, economic, and social approach to sustainability. Facilities 2016, 34, 264-288. [CrossRef]

23. Pinzone, M.; Lettieri, E.; Masella, C. Proactive environmental strategies in healthcare organisations: Drivers and barriers in Italy. J. Bus. Ethics 2015, 131, 183-197. [CrossRef]

24. Cowie, J.; Nicoll, A.; Dimova, E.D.; Campbell, P.; Duncan, E.A. The barriers and facilitators influencing the sustainability of hospital-based interventions: A systematic review. BMC Health Serv. Res. 2020, 20, 1-27. [CrossRef]

25. Dhagarra, D.; Goswami, M.; Sarma, P.R.S.; Choudhury, A. Big Data and blockchain supported conceptual model for enhanced healthcare coverage. Bus. Process Manag. J. 2019, 25, 1612-1632. [CrossRef]

26. Blackwell, G. The future of IT in healthcare. Inform. Health Soc. Care 2008, 33, 211-326. [CrossRef]

27. Ibn-Mohammed, T.; Mustapha, K.B.; Godsell, J.; Adamu, Z.; Babatunde, K.A.; Akintade, D.D.; Acquaye, A.; Fujii, H.; Ndiaye, M.M.; Yamoah, F.A.; et al. A critical review of the impacts of COVID-19 on the global economy and ecosystems and opportunities for circular economy strategies. Resour. Conserv. Recycl. 2020, 164, 105169. [CrossRef]

28. Dunphy, J.L. Healthcare professionals' perspectives on environmental sustainability. Nurs. Ethics 2014, 21, 414-425. [CrossRef]

29. Ament, S.M.; Gillissen, F.; Moser, A.; Maessen, J.M.; Dirksen, C.D.; Von Meyenfeldt, M.F.; Van der Weijden, T. Factors associated with sustainability of 2 quality improvement programs after achieving early implementation success. A qualitative case study. J. Eval. Clin. Pract. 2017, 23, 1135-1143. [CrossRef]

30. Bridges, J.; May, C.; Fuller, A.; Griffiths, P.; Wigley, W.; Gould, L.; Barker, H.; Libberton, P. Optimising impact and sustainability: A qualitative process evaluation of a complex intervention targeted at compassionate care. BMJ Qual. Saf. 2017, 26, 970-977. [CrossRef]

31. Gramlich, L.M.; Sheppard, C.E.; Wasylak, T.; Gilmour, L.E.; Ljungqvist, O.; Basualdo-Hammond, C.; Nelson, G. Implementation of Enhanced Recovery After Surgery: A strategy to transform surgical care across a health system. Implement. Sci. 2017, 12, 1-17. [CrossRef]

32. Jangland, E.; Gunningberg, L. Improving patient participation in a challenging context: A 2-year evaluation study of an implementation project. J. Nurs. Manag. 2017, 25, 266-275. [CrossRef]

33. Mitchell, S.E.; Weigel, G.M.; Laurens, V.; Martin, J.; Jack, B.W. Implementation and adaptation of the re-engineered discharge (RED) in five California hospitals: A qualitative research study. BMC Health Serv. Res. 2017, 17, 1-14. [CrossRef]

34. Fleiszer, A.R.; Semenic, S.E.; Ritchie, J.A.; Richer, M.C.; Denis, J.L. An organizational perspective on the long-term sustainability of a nursing best practice guidelines program: A case study. BMC Health Serv. Res. 2015, 15, 1-16. [CrossRef]

35. Frykman, M.; Von Thiele Schwarz, U.; Athlin, Å.M.; Hasson, H.; Mazzocato, P. The work is never ending: Uncovering teamwork sustainability using realistic evaluation. J. Health Organ. Manag. 2017, 31, 64-81. [CrossRef]

36. Ilott, I.; Gerrish, K.; Eltringham, S.A.; Taylor, C.; Pownall, S. Exploring factors that influence the spread and sustainability of a dysphagia innovation: An instrumental case study. BMC Health Serv. Res. 2016, 16, 1-14. [CrossRef] [PubMed]

37. Glasgow, J.M.; Yano, E.M.; Kaboli, P.J. Impacts of organizational context on quality improvement. Am. J. Med Qual. 2013, 28, 196-205. [CrossRef]

38. Robert, G.; Morrow, E.; Maben, J.; Griffiths, P.; Callard, L. The adoption, local implementation and assimilation into routine nursing practice of a national quality improvement programme: The Productive Ward in England. J. Clin. Nurs. 2011, 20, 1196-1207. [CrossRef]

39. Townend, W.K. Safe management of wastes from health care activities. Bull. World Health Organ. 2001, 79, 171.

40. Balsara, S.; Jain, P.K.; Ramesh, A. An integrated methodology to overcome barriers to climate change mitigation strategies: A case of the cement industry in India. Environ. Sci. Pollut. Res. 2021, 28, 20451-20475. [CrossRef]

41. Quitmann, C.; Sauerborn, R.; Herrmann, A. Gaps in Reporting Greenhouse Gas Emissions by German Hospitals-A Systematic Grey Literature Review. Sustainability 2021, 13, 1430. [CrossRef]

42. Chepelev, L.L.; Rybicki, F.J. Sterilization of 3D Printed Parts Used as Medical Devices in the COVID-19 Pandemic. In 3D Printing in Medicine and Its Role in the COVID-19 Pandemic; Springer: Berlin, Germany, 2021; pp. 107-113.

43. Naldemirci, Ö.; Wolf, A.; Elam, M.; Lydahl, D.; Moore, L.; Britten, N. Deliberate and emergent strategies for implementing person-centred care: A qualitative interview study with researchers, professionals and patients. BMC Health Serv. Res. 2017, 17, 1-10. [CrossRef]

44. Brady, P.W.; Brinkman, W.B.; Simmons, J.M.; Yau, C.; White, C.M.; Kirkendall, E.S.; Schaffzin, J.K.; Conway, P.H.; Vossmeyer, M.T. Oral antibiotics at discharge for children with acute osteomyelitis: A rapid cycle improvement project. BMJ Qual. Saf. 2014, 23, 499-507. [CrossRef] [PubMed]

45. Matthew-Maich, N.; Ploeg, J.; Dobbins, M.; Jack, S. Supporting the uptake of nursing guidelines: What you really need to know to move nursing guidelines into practice. Worldviews Evid. Based Nurs. 2013, 10, 104-115. [CrossRef] 
46. Campbell, S.; Pieters, K.; Mullen, K.A.; Reece, R.; Reid, R.D. Examining sustainability in a hospital setting: Case of smoking cessation. Implement. Sci. 2011, 6, 1-11. [CrossRef]

47. Klarenbeek, S.E.; Schuurbiers-Siebers, O.C.; Van den Heuvel, M.M.; Prokop, M.; Tummers, M. Barriers and Facilitators for Implementation of a Computerized Clinical Decision Support System in Lung Cancer Multidisciplinary Team MeetingsA Qualitative Assessment. Biology 2021, 10, 9. [CrossRef]

48. Hussain, M.; Ajmal, M.M.; Gunasekaran, A.; Khan, M. Exploration of social sustainability in healthcare supply chain. J. Clean. Prod. 2018, 203, 977-989. [CrossRef]

49. Nordmark, S.; Zingmark, K.; Lindberg, I. Process evaluation of discharge planning implementation in healthcare using normalization process theory. BMC Med. Inform. Decis. Mak. 2016, 16, 1-10. [CrossRef] [PubMed]

50. Bernstein, E.; Topp, D.; Shaw, E.; Girard, C.; Pressman, K.; Woolcock, E.; Bernstein, J. A preliminary report of knowledge translation: Lessons from taking screening and brief intervention techniques from the research setting into regional systems of care. Acad. Emerg. Med. 2009, 16, 1225-1233. [CrossRef]

51. Green, S.A.; Bell, D.; Mays, N. Identification of factors that support successful implementation of care bundles in the acute medical setting: A qualitative study. BMC Health Serv. Res. 2017, 17, 1-8. [CrossRef]

52. Bhanbhro, S.; Gee, M.; Cook, S.; Marston, L.; Lean, M.; Killaspy, H. Recovery-based staff training intervention within mental health rehabilitation units: A two-stage analysis using realistic evaluation principles and framework approach. BMC Psychiatry 2016, 16, 1-14. [CrossRef]

53. McClung, L.; Obasi, C.; Knobloch, M.J.; Safdar, N. Health care worker perspectives of their motivation to reduce health care-associated infections. Am. J. Infect. Control 2017, 45, 1064-1068. [CrossRef]

54. Gould, D.J.; Hale, R.; Waters, E.; Allen, D. Promoting health workers' ownership of infection prevention and control: Using normalization process theory as an interpretive framework. J. Hosp. Infect. 2016, 94, 373-380. [CrossRef]

55. Sanchez, S.H.; Sethi, S.S.; Santos, S.L.; Boockvar, K. Implementing medication reconciliation from the planner's perspective: A qualitative study. BMC Health Serv. Res. 2014, 14, 1-10. [CrossRef]

56. Bergh, A.M.; Kerber, K.; Abwao, S.; Johnson, J.D.G.; Aliganyira, P.; Davy, K.; Gamache, N.; Kante, M.; Ligowe, R.; Luhanga, R.; et al. Implementing facility-based kangaroo mother care services: Lessons from a multi-country study in Africa. BMC Health Serv. Res. 2014, 14, 1-10. [CrossRef] [PubMed]

57. Mazzocato, P.; Holden, R.J.; Brommels, M.; Aronsson, H.; Bäckman, U.; Elg, M.; Thor, J. How does lean work in emergency care? A case study of a lean-inspired intervention at the Astrid Lindgren Children's hospital, Stockholm, Sweden. BMC Health Serv. Res. 2012, 12, 1-3. [CrossRef] [PubMed]

58. Udenigwe, O.; Okonofua, F.E.; Ntoimo, L.F.; Imongan, W.; Igboin, B.; Yaya, S. Perspectives of policymakers and health providers on barriers and facilitators to skilled pregnancy care: Findings from a qualitative study in rural Nigeria. BMC Pregnancy Childbirth 2021, 21, 1-14. [CrossRef]

59. Hillary, R. Environmental management systems and the smaller enterprise. J. Clean. Prod. 2004, 12, 561-569. [CrossRef]

60. De Vries, J.; Huijsman, R. Supply chain management in health services: An overview. Supply Chain Manag. Int. J. 2011, 16, 159-165. [CrossRef]

61. World Health Organization. Safe Management of Wastes from Health-Care Activities: A Summary (No. WHO/FWC/WSH/17.05); World Health Organization: Geneva, Switzerland, 2017.

62. Scavarda, A.; Daú, G.L.; Scavarda, L.F.; Korzenowski, A.L. A proposed healthcare supply chain management framework in the emerging economies with the sustainable lenses: The theory, the practice, and the policy. Resour. Conserv. Recycl. 2019, 141, 418-430. [CrossRef]

63. Acquaye, A.; Ibn-Mohammed, T.; Genovese, A.; Afrifa, G.A.; Yamoah, F.A.; Oppon, E. A quantitative model for environmentally sustainable supply chain performance measurement. Eur. J. Oper. Res. 2018, 269, 188-205. [CrossRef]

64. Li, Y.; Mathiyazhagan, K. Application of DEMATEL approach to identify the influential indicators towards sustainable supply chain adoption in the auto components manufacturing sector. J. Clean. Prod. 2018, 172, 2931-2941. [CrossRef]

65. Wu, J.Z.; Santoso, C.H.; Roan, J. Key factors for truly sustainable supply chain management: An investigation of the coal industry in Indonesia. Int. J. Logist. Manag. 2017, 28, 1196-1217. [CrossRef]

66. Zeng, H.; Chen, X.; Xiao, X.; Zhou, Z. Institutional pressures, sustainable supply chain management, and circular economy capability: Empirical evidence from Chinese eco-industrial park firms. J. Clean. Prod. 2017, 155, 54-65. [CrossRef]

67. Malek, J.; Desai, T.N. Prioritization of sustainable manufacturing barriers using Best Worst Method. J. Clean. Prod. 2019, 226, 589-600. [CrossRef]

68. Mangla, S.K.; Govindan, K.; Luthra, S. Prioritizing the barriers to achieve sustainable consumption and production trends in supply chains using fuzzy Analytical Hierarchy Process. J. Clean. Prod. 2017, 151, 509-525. [CrossRef]

69. Govindan, K.; Kaliyan, M.; Kannan, D.; Haq, A.N. Barriers analysis for green supply chain management implementation in Indian industries using analytic hierarchy process. Int. J. Prod. Econ. 2014, 147, 555-568. [CrossRef]

70. Wang, Z.; Mathiyazhagan, K.; Xu, L.; Diabat, A. A decision making trial and evaluation laboratory approach to analyze the barriers to Green Supply Chain Management adoption in a food packaging company. J. Clean. Prod. 2016, 117, 19-28. [CrossRef]

71. Walker, H.; Jones, N. Sustainable supply chain management across the UK private sector. Supply Chain Manag. Int. J. 2012, 17, 15-28. [CrossRef] 
72. Liu, A.M.; Fellows, R.; Tuuli, M.M. The role of corporate citizenship values in promoting corporate social performance: Towards a conceptual model and a research agenda. Constr. Manag. Econ. 2011, 29, 173-183. [CrossRef]

73. Jiang, B. Implementing supplier codes of conduct in global supply chains: Process explanations from theoretic and empirical perspectives. J. Bus. Ethics 2009, 85, 77-92. [CrossRef]

74. Park-Poaps, H.; Rees, K. Stakeholder forces of socially responsible supply chain management orientation. J. Bus. Ethics 2010, 92, 305-322. [CrossRef]

75. Gupta, P.; Anand, S.; Gupta, H. Developing a roadmap to overcome barriers to energy efficiency in buildings using best worst method. Sustain. Cities Soc. 2017, 31, 244-259. [CrossRef]

76. Cagno, E.; Worrell, E.; Trianni, A.; Pugliese, G. A novel approach for barriers to industrial energy efficiency. Renew. Sustain. Energy Rev. 2013, 19, 290-308. [CrossRef]

77. Cagno, E.; Trianni, A.; Abeelen, C.; Worrell, E.; Miggiano, F. Barriers and drivers for energy efficiency: Different perspectives from an exploratory study in the Netherlands. Energy Convers. Manag. 2015, 102, 26-38. [CrossRef]

78. Winston, N. Regeneration for sustainable communities? Barriers to Implementing Sustainable Urban areas in housing. Sustain. Dev. 2010, 18, 319-330. [CrossRef]

79. Hirst, E.; Brown, M. Closing the efficiency gap: Barriers to the efficient use of energy. Resour. Conserv. Recycl. 1990, 3, 267-281. [CrossRef]

80. Mohee, R. Medical wastes characterisation in healthcare institutions in Mauritius. Waste Manag. 2005, 25, 575-581. [CrossRef]

81. Jameton, A.; Pierce, J. Environment and health: 8. Sustainable health care and emerging ethical responsibilities. CMAJ 2001, 164, 365-369. [PubMed]

82. Reike, D.; Vermeulen, W.J.; Witjes, S. The circular economy: New or refurbished as CE 3.0?-Exploring controversies in the conceptualization of the circular economy through a focus on history and resource value retention options. Resour. Conserv. Recycl. 2018, 135, 246-264. [CrossRef]

83. World Health Organization. Circular Economy and Health: Opportunities and Risk; World Health Organization Regional Office for Europe: Copenhagen, Denmark, 2018.

84. Daú, G.; Scavarda, A.; Scavarda, L.F.; Portugal, V.J.T. The healthcare sustainable supply chain 4.0: The circular economy transition conceptual framework with the corporate social responsibility mirror. Sustainability 2019, 11, 3259. [CrossRef]

85. Zikopoulos, P.; Eaton, C. Understanding Big Data: Analytics for Enterprise Class Hadoop and Streaming Data; McGraw-Hill Osborne Media: New York, NY, USA, 2011.

86. Shahid, N.; Rappon, T.; Berta, W. Applications of artificial neural networks in health care organizational decision-making: A scoping review. PLoS ONE 2019, 14, e0212356. [CrossRef] [PubMed]

87. Pesqueira, A.; Sousa, M.J.; Rocha, Á. Big Data Skills Sustainable Development in Healthcare and Pharmaceuticals. J. Med. Syst. 2020, 44, 1-15. [CrossRef]

88. Wang, Y.; Kung, L.; Byrd, T.A. Big data analytics: Understanding its capabilities and potential benefits for healthcare organizations. Technol. Forecast. Soc. Chang. 2018, 126, 3-13. [CrossRef]

89. Manogaran, G.; Lopez, D. A survey of big data architectures and machine learning algorithms in healthcare. Int. J. Biomed. Eng. Technol. 2017, 25, 182-211. [CrossRef]

90. Priyanka, K.; Kulennavar, N. A survey on big data analytics in health care. Int. J. Comput. Sci. Inf. Technol. 2014, 5, 5865-5868.

91. Viceconti, M.; Hunter, P.; Hose, R. Big data, big knowledge: Big data for personalized healthcare. IEEE J. Biomed. Health Inform. 2015, 19, 1209-1215. [CrossRef]

92. Archenaa, J.; Anita, E.M. A survey of big data analytics in healthcare and government. Procedia Comput. Sci. 2015, 50, 408-413. [CrossRef]

93. Ngiam, K.Y.; Khor, W. Big data and machine learning algorithms for health-care delivery. Lancet Oncol. 2019, 20, e262-e273. [CrossRef]

94. Char, D.S.; Shah, N.H.; Magnus, D. Implementing machine learning in health care-Addressing ethical challenges. N. Engl. J. Med. 2018, 378, 981-983. [CrossRef]

95. Kaur, P.; Sharma, M.; Mittal, M. Big data and machine learning based secure healthcare framework. Procedia Comput. Sci. 2018, 132, 1049-1059. [CrossRef]

96. Dey, N.; Das, H.; Naik, B.; Behera, H.S. (Eds.) Big Data Analytics for Intelligent Healthcare Management; Academic Press: London, UK, 2019.

97. Mahfoud, H.; El Barkany, A.; El Biyaali, A. Preventive maintenance optimization in healthcare domain: Status of research and perspective. J. Qual. Reliab. Eng. 2016, 2016, 5314312. [CrossRef]

98. Kuo, M.H. Opportunities and challenges of cloud computing to improve health care services. J. Med. Internet Res. 2011, 13, e67. [CrossRef] [PubMed]

99. Ali, O.; Soar, J.; Shrestha, A. Perceived potential for value creation from cloud computing: A study of the Australian regional government sector. Behav. Inf. Technol. 2018, 37, 1157-1176. [CrossRef]

100. Ali, O.; Shrestha, A.; Soar, J.; Wamba, S.F. Cloud computing-enabled healthcare opportunities, issues, and applications: A systematic review. Int. J. Inf. Manag. 2018, 43, 146-158. [CrossRef]

101. Chen, M.; Ma, Y.; Song, J.; Lai, C.F.; Hu, B. Smart clothing: Connecting human with clouds and big data for sustainable health monitoring. Mob. Netw. Appl. 2016, 21, 825-845. [CrossRef] 
102. Lian, J.W.; Yen, D.C.; Wang, Y.T. An exploratory study to understand the critical factors affecting the decision to adopt cloud computing in Taiwan hospital. Int. J. Inf. Manag. 2014, 34, 28-36. [CrossRef]

103. Ramachandran, M. Software security requirements management as an emerging cloud computing service. Int. J. Inf. Manag. 2016, 36, 580-590. [CrossRef]

104. Ahuja, S.P.; Mani, S.; Zambrano, J. A Survey of the State of Cloud Computing in Healthcare. Netw. Commun. Technol. 2012, 1, 12-19. [CrossRef]

105. Pussewalage, H.S.G.; Oleshchuk, V.A. Privacy preserving mechanisms for enforcing security and privacy requirements in E-health solutions. Int. J. Inf. Manag. 2016, 36, 1161-1173. [CrossRef]

106. Sultan, N. Discovering the potential of cloud computing in accelerating the search for curing serious illnesses. Int. J. Inf. Manag. 2014, 34, 221-225. [CrossRef]

107. Diwani, S.; Mishol, S.; Kayange, D.S.; Machuve, D.; Sam, A. Overview applications of data mining in health care: The case study of Arusha region. Int. J. Comput. Eng. Res. 2013, 3, 73-77.

108. Durairaj, M.; Ranjani, V. Data mining applications in healthcare sector: A study. Int. J. Sci. Technol. Res. 2013,2 , $29-35$.

109. Koh, H.C.; Tan, G. Data mining applications in healthcare. J. Healthc. Inf. Manag. 2011, 19, 64-72.

110. Jang, H.L.; Lee, Y.S.; An, J.Y. Application of social network analysis to health care sectors. Healthc. Inform. Res. 2012, 18, 44-56. [CrossRef]

111. Wang, F.; Srinivasan, U.; Uddin, S.; Chawla, S. Application of network analysis on healthcare. In Proceedings of the 2014 IEEE/ACM International Conference on Advances in Social Networks Analysis and Mining (ASONAM 2014), Beijing, China, 17-20 August 2014; pp. 596-603.

112. McCurdie, T.; Sanderson, P.; Aitken, L.M. Applying social network analysis to the examination of interruptions in healthcare. Appl. Ergon. 2018, 67, 50-60. [CrossRef]

113. Stanton, N.A. Representing distributed cognition in complex systems: How a submarine returns to periscope depth. Ergonomics 2014, 57, 403-418. [CrossRef]

114. Kankanhalli, A.; Hahn, J.; Tan, S.; Gao, G. Big data and analytics in healthcare: Introduction to the special section. Inf. Syst. Front. 2016, 18, 233-235. [CrossRef]

115. Paliwal, M.; Kumar, U.A. Neural networks and statistical techniques: A review of applications. Expert Syst. Appl. 2009, 36, 2-17. [CrossRef]

116. Gupta, H. Evaluating service quality of airline industry using hybrid best worst method and VIKOR. J. Air Transp. Manag. 2018, 68, 35-47. [CrossRef]

117. Shojaei, P.; Haeri SA, S.; Mohammadi, S. Airports evaluation and ranking model using Taguchi loss function, best-worst method and VIKOR technique. J. Air Transp. Manag. 2018, 68, 4-13. [CrossRef]

118. Tian, Z.P.; Wang, J.Q.; Zhang, H.Y. An integrated approach for failure mode and effects analysis based on fuzzy best-worst, relative entropy, and VIKOR methods. Appl. Soft Comput. 2018, 72, 636-646. [CrossRef]

119. Zadeh, L.A. Fuzzy Sets. Inf. Control. 1965, 8, 338-353. [CrossRef]

120. Rezaei, J. Best-worst multi-criteria decision-making method. Omega 2015, 53, 49-57. [CrossRef]

121. Opricovic, S. Multi-Criteria Optimization of Civil Engineering Systems. Ph.D. Thesis, Faculty of Civil Engineering of the University of Belgrade, Beograd, Serbia, 1998.

122. Opricovic, S.; Tzeng, G.H. Multicriteria planning of post-earthquake sustainable reconstruction. Comput. Aided Civ. Infrastruct. Eng. 2002, 17, 211-220. [CrossRef]

123. Opricovic, S. Fuzzy VIKOR with an application to water resources planning. Expert Syst. Appl. 2011, 38, 12983-12990. [CrossRef]

124. Sanayei, A.; Mousavi, S.F.; Yazdankhah, A. Group decision making process for supplier selection with VIKOR under fuzzy environment. Expert Syst. Appl. 2010, 37, 24-30. [CrossRef]

125. Sharma, A.; Borah, S.B.; Moses, A.C. Responses to COVID-19: The role of governance, healthcare infrastructure, and learning from past pandemics. J. Bus. Res. 2021, 122, 597-607. [CrossRef] [PubMed]

126. Clarkson, J.; Dean, J.; Ward, J.; Komashie, A.; Bashford, T. A systems approach to healthcare: From thinking to practice. Future Healthc. J. 2018, 5, 151-155. [CrossRef]

127. Johnson \& Johnson Services. The Growing Importance of More Sustainable Products in the Global Health Care Industry. 2012. Available online: https:/ / www.jnj.com/sites/default/files/pdf/JNJ-Sustainable-Products-White-Paper-092512.pdf (accessed on 27 November 2020). 